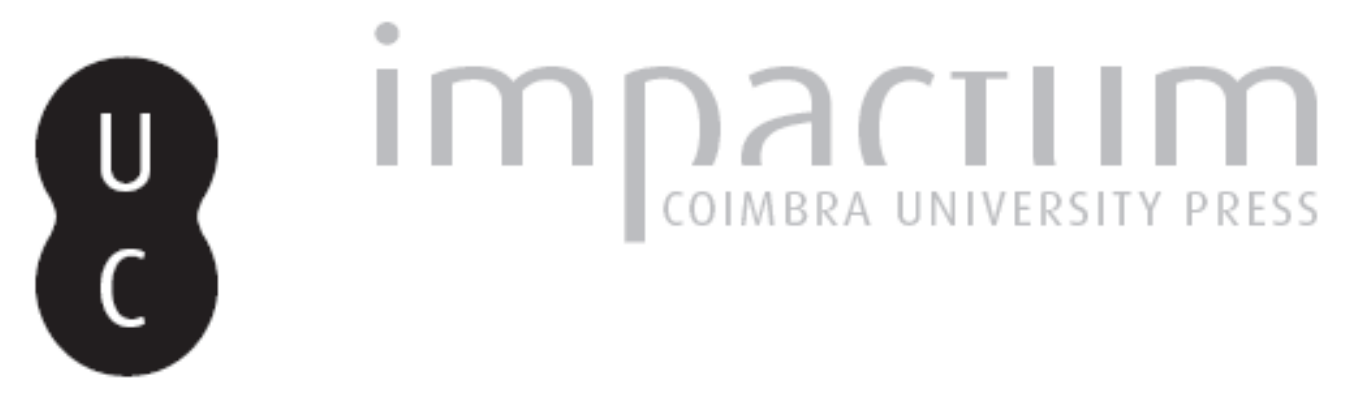

\title{
Antero romântico
}

Autor(es): $\quad$ Pires, António M. B. Machado

Publicado por: Imprensa da Universidade de Coimbra

URL persistente:

URl:http://hdl.handle.net/10316.2/43744

DOI:

DOI:https://doi.org/10.14195/2183-8925_13_7

Accessed : $\quad$ 26-Apr-2023 12:15:32

A navegação consulta e descarregamento dos títulos inseridos nas Bibliotecas Digitais UC Digitalis, UC Pombalina e UC Impactum, pressupõem a aceitação plena e sem reservas dos Termos e Condições de Uso destas Bibliotecas Digitais, disponíveis em https://digitalis.uc.pt/pt-pt/termos.

Conforme exposto nos referidos Termos e Condições de Uso, o descarregamento de títulos de acesso restrito requer uma licença válida de autorização devendo o utilizador aceder ao(s) documento(s) a partir de um endereço de IP da instituição detentora da supramencionada licença.

Ao utilizador é apenas permitido o descarregamento para uso pessoal, pelo que o emprego do(s) título(s) descarregado(s) para outro fim, designadamente comercial, carece de autorização do respetivo autor ou editor da obra.

Na medida em que todas as obras da UC Digitalis se encontram protegidas pelo Código do Direito de Autor e Direitos Conexos e demais legislação aplicável, toda a cópia, parcial ou total, deste documento, nos casos em que é legalmente admitida, deverá conter ou fazer-se acompanhar por este aviso. 
REVISTA DE HISTÓRIA DAS IDEIAS 13

\section{Antero de Quental}

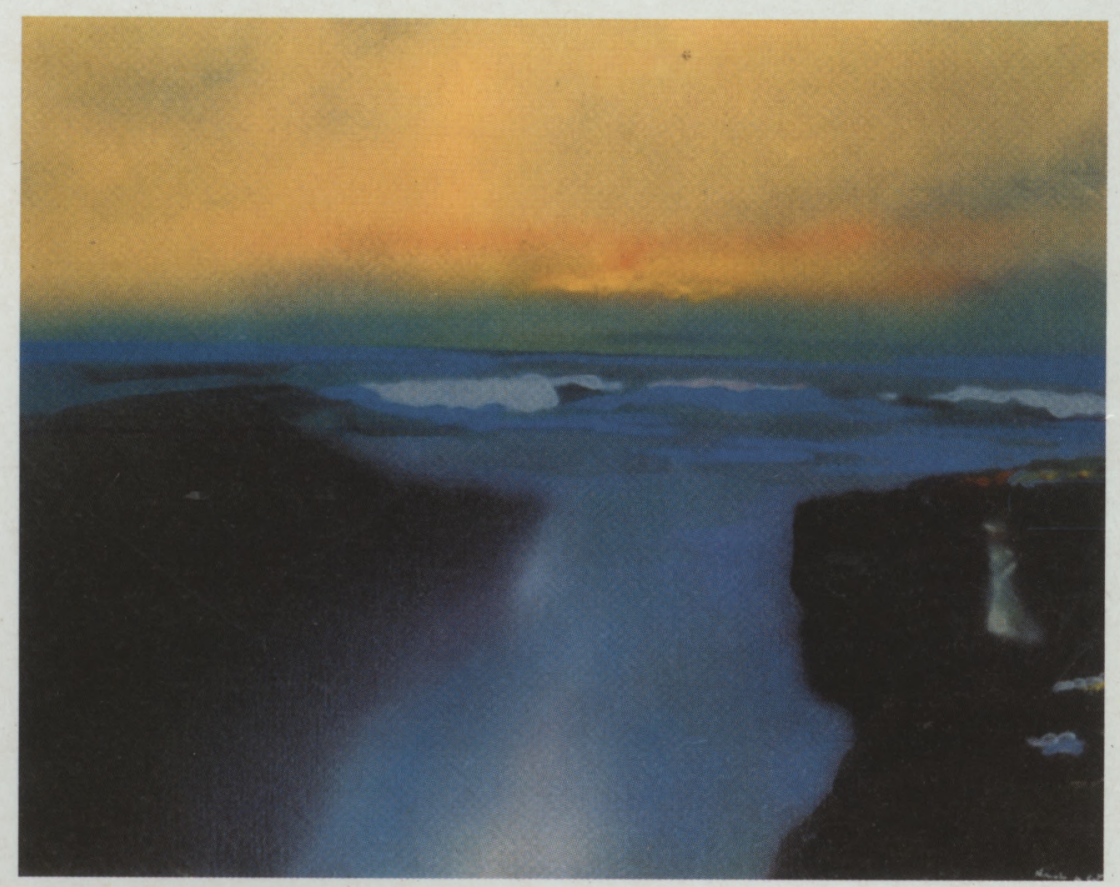

INSTITUTO DE HISTÓRIA E TEORIA DAS IDEIAS FACULDADE DE LETRAS

COIMBRA 1991 


\section{ANTERO ROMÂNTICO}

Que é o Romantismo? Uma unidade de alma e natureza, tornando esta partícipe e cúmplice dos nossos sentimentos? Uma pluralidade de estados de alma fundidos num só, exaltado e dolente? Uma infinidade de "definições" de carácter subjectivo podem ser tentadas e enchem a vasta bibliografia do Romantismo.

Mas, para o caso português, e para o caso de Antero, convirá atermo-nos às definições de natureza periodológica primeiro. De resto, têm-se discutido as balizas do Romantismo português: uma época difusa, com alargados limites cronológicos e diversos traços culturais, que se inicia convencionalmente em 1825 com o Camões de Garrett, mas de facto só encontra pressupostos sociais e políticos de realização após o triunfo do Liberalismo em 1834. Filho de um "bravo do Mindelo", de um homem da primeira geração romântica, Antero, nascido em 1842, está etariamente ao lado dos homens da geração realista, naturalista, socialista e "revolucionária" das décadas de 60 e 70, por isso mesmo a tão celebrada Geração de 70. Estes os fenómenos de superfície que a cronologia levanta ao leitor de Antero, Eça, Oliveira Martins, Teófilo, Batalha Reis, entre os principais. Mas o Príncipe da Mocidade é contemporâneo, ainda que bastante mais novo, de Camilo, de Soares de Passos, de António Lopes de Mendonça, de Fontes Pereira de Melo, i. e., de gente da segunda geração romântica, da Geração de 50, que ficou "marcada" pelo "último" (não seria o último!) romantismo, o ultra-romantismo, pela Regeneraçãoe pelo Fontismo, pelos primeiros socialistas, como Sousa Brandão ou Vieira da Silva.

\footnotetext{
* Universidade dos Açores.
} 
O Romantismo português é tardio e em muitos aspectos incompleto. As suas fontes principais são as francesas e as inglesas. Das francesas destacam-se Chateaubriand (como Nemésio bem salientou nas Relações Francesas do Romantismo português, Coimbra, 1936), Lamartine, V. Hugo; das inglesas, Byron, Walter Scott, Young são nomes dos principais. Os românticos da $1^{a}$ geração não assimilaram 0 romantismo alemão, por exemplo, Novalis e Heine, que só a geração de 70 vai ler. Mesmo Coleridge, Wordsworth, Shelley, Keats são autores ingleses que Pessoa difundiu no Orpheu. E nos nossos dias, Agustina Bessa Luís retoma o universo camiliano através de uma visão dostoievskiana do mundo que bebeu em Raul Brandão, não deixando também de dever alguma coisa a Novalis e a Holderlin, autores que escaparam a Garrett, Herculano e a Camilo. Novalis e Heine não escaparam, porém, a Eça e à sua geração, como veremos.

Mas o Romantismo como fenómeno estético alargado, como atitude perante a vida e forma de sensibilidade, não se limitou a atravessar a geração de 70. Não é, aliás, por acaso que se fala de neo-romantismo no fim de século, não se ignora a herança romântica expressa no neo-garrettismo de um António Nobre ou no saudosismo de Teixeira de Pascoais. Este é, a bem dizer, em muitos aspectos, talvez o último dos românticos, pelo seu irracionalismo, pela sua mística, pela sua crença intuicionista no Homem, pela sua esperança sebástica. A saudade garrettiana é agora saudade do passado e saudade do futuro.

Os românticos são, ao mesmo tempo, os portadores de uma estética do egocentrismo, da egolatria, do primado da sensibilidade sobre a Razão, de uma platónica voz do Inconsciente e das forças tumultuárias do génio, mas são também os arautos do progresso - do Progresso e das Luzes, o que levou Alberto Ferreira a distinguir o Romantismo iluminista do Panorama e da difusão dos "conhecimentos úteis", do sentimental, o dos Euricos, das Hermengardas, das Marias do Frei Luís de Sousa, das donzelas desta estirpe, que morrem tuberculosas em lances sublimes ou adornam as barbacãs de castelos medievais. Uma longa família, que vai desde obras exemplares aos dramalhões românticos dos meados do século.

Quando falha o projecto das obras públicas do Cabralismo, embora se consigam já as primeiras instalações de luz a gás, como a do Conde de Farrobo nas Laranjeiras no ano de 1840, quando, finalmente com a Regeneração e o Fontismo se começa o Caminho de Ferro (primeiro 
troçoLisboa-Carregado em 1856), um homem nascido em Lisboa, mas criado no Norte, Camilo Castelo Branco, sintetizaria, com o seu exemplo de vida e com o traço genial da sua obra romanesca, a aliança entre génio, loucura e sociedade. A sua dostoiesvkiana metafísica da dor, a sua dialéctica de queda e redenção, crime e castigo, sublime e grotesco, justiçae injustiça, traduzem uma visãotumultuária, passional, arrebatada de um Portugal meados do século XIX ainda impregnado de vivências aristocráticas-senhoriais e autoritárias dos séculos XVIII ou XVII. Centremo-nos no Camilo dos anos 50. Quando Antero é ainda uma criança de dez ou doze anos, quando recebia aulas de Francês de Castilho e fez as primeiras viagens de Ponta Delgada ao Continente, Camilo (que haveria de participar na "romântica" batalha da famosa Questão Coimbrã) estava pelo Porto, frequentando os cafés e as boémias literárias, os salões de Maria Browne ou de Fanny Owen.

Rebuçado na sua capa escocesa, Camilo (que haveria de ir parar à cadeia da Relação do Porto por causa do escândalo com Ana Plácido), era um dos mais activos elementos da juventude irrequieta do Porto anos 50, como nos conta Ramalho Ortigão nas páginas que lhe dedicou no prefácio da edição monumental do Amor de Perdição (1889) $\left(^{1}\right)$. As questões jornalísticas, mais de uma dezena de anos antes da "romântica" Questão Coimbrã, resolviam-se por vezes em lances menos jornalísticos e mais directos, como este do Novais da Pátria. Ouçamos Ramalho (texto citado):

"As controvérsias jornalísticas degeneravam amiudadamente em vias de facto. O jornalista Novais Vieira, o Novais dos Óculos ou Novais da Pátria, como variadamente lhe chamavam, publicou um artigo de maledicência, em que três homens Camilo, Faustino Xavier de Novais e um outro cujo nome me esquece viram alusões pessoais que resolveram punir. No dia dessa publicação malfadada, Faustino, chegando ao teatro de $\mathrm{S}$. João, onde o redactor da Pátria ia todas as noites, encontrou no pátio de entrada Camilo, rebuçado no plaid com o casse-tête bamboleando pendente da sôga.

- Quem lhe dá aqui sou eu, que cheguei primeiro - disse Camilo.

Faustino subia à primeira ordem, onde Novais Vieira assistia de um camarote ao espectáculo. À porta dêsse camarote, sobraçando uma

(') Texto reunido posteriormente em Figuras e Questões Literárias I- "Camões, Garrett, Camilo e Eça". 
longa chibatada de picaria, passeava o anónimo a que acima aludi. Este personagem dirigiu-se atenciosamente a Faustino Xavier de Novais.

- Se V. Ex. a vem também para espancar oSr. Novais Vieira, rogo-lhe o obséquio de esperar de preferência lá em baixo.

- Lá em baixo está o esperando já, com lugar tomado, o Sr. Camilo Castelo Branco.

- Nesse caso suplicar-lhe-ei que me faça a fineza de ir para êsse primeiro patamar. Eu encaminharei para lá os passos do Sr. Novais Vieira, para cujo primeiro encontro sou eu que tenho a vez. Há dez minutos que aqui estou. Assim, bem vê...

O drama da expiação, a que o pobre Novais da Pátria estava destinado a figurar nessa noite infausta, foi pungente mas breve. Dentro de poucos minutos, o desventurado saía do camarote em que se encontrava, era rapidamente estreado com duas chibatadas, galgava como um gamo ao primeiro lanço de escada; daí, rechaçado a soco, vinha de um só pulo cair sob o casse-tête de Camilo, no esteirão do fundo, e era consecutivamente levadoem braços à botica mais próxima, com uma brecha na cabeça e duas costelas partidas".

Alguns anos mais tarde, Camilo haveria de tomar lugar na famosa batalha de folhetins da Questão Coimbrã (1865-1866), com as suas "Vaidades irritadas e irritantes" (Janeiro de 1866) e Antero, ainda no verdor dos seus vinte e três anos, haveria de bater-se em duelo, romanticamente, com Ramalho, nos arredores do Porto. E, de resto românticos eram os versos "revolucionários" das Odes Modernas, "poesia moderna, voz de Revolução". Versos em que a História e a Justiça, o Homem e as Religiões são protagonistas de uma epopeia da Humanidade, cantada em tom revolucionário, exaltado, onde ainda ecoam os tons solenes e pesados da romântica Harpa do Crente, do "velho mestre" Herculano, com quem Antero confessou ter aprendido a ser poeta... Versos às vezes pesados, mal conseguidos, prosaicos.

Mais é justamente ao motivo da "Cruz" que o $1^{\circ}$ Fradique-Antero vai buscar a raiz do soneto "A cruz dizia..."

A cruz dizia à terra onde assentava,

Ao val florido, ao monte nu e mudo:

- "Que és tu, abismo e jaula, aonde tudo

Vive na dor e em luta cega e brava? 


\section{Antero romântico}

Sempre em trabalho, condenada escrava,

Que fazes tu de grande e bom contudo?

Resignada, és só lodo, informe e rudo;

Revoltosa, és só fogo e hórrida lava...

Mas a mim não há alta e livre serra

Que me possa igualar! Amor, firmeza,

Sou eu só - sou a paz... tu és a guerra!

Sou o espírito, a luz! tu és tristeza.

Ó lodo escuro e vil!..." Porém a terra

Respondeu - "Cruz, eu sou a natureza!"

\section{Antero de Quental}

O diálogo "Cruz/Terra" significa a "romântica" pretensão da vitória da Cruz, símbolo de influência da poesia religiosa de Herculano. Significa também a vitória de luz sobre as trevas, nessa alternativa de luz apolínea com as trevas dionisíacas que caracteriza a diatribe psíquica anteriana, segundo a clássica explicação de António Sérgio. De resto, o soneto, na boa tradição bocageana, é uma forma apta a captar a sentimentalidade romântica, que Antero, habitualmente nos sonetos corporiza em diálogos ou em invocações e apóstrofes.

Este Fradique heterónimo de Antero nos anos 60, é o primeiro Fradique, o da época em que aquela geração, admiradora de Baudelaire, lembra o seu "romantismo" medular, marcando as vivências académicas coimbrãs.

"Naqueles tempos, segundo a fórmula do Evangelho, o romantismo estava nas nossas almas. Fazíamos devotamente oração diante do busto de Shakespeare" - escreve Eça na "Carta" (a Carlos Mayer), coligida nas Prosas Bárbaras ( ${ }^{2}$ ). Nesse retrato da Coimbra estudantil são ídolos Voltaire, Diderot, Rousseau, Napoleão, Novalis, Heine, enfim, o quarto de Carlos Mayer é um "Hotel Rambouillet do romantismo coimbrão". "Tínhamos (...) um idealismo doentio e dissolvente. $\mathrm{O}$ nosso grande compositor era Beethoven". Mas - acrescenta - "os que

(2) Crónica de 3 de Novembro de 1867, na Gazeta de Portugal, Eça tem, na altura, 22 anos. 
desceram às regióes românticas ficaram com a alma doente, febril, ansiada, nostálgica. Aí está como se explica toda esta geração moderna, contemplativa e doente!" (Ibidem). É então que Eça cita o Príncipe da Mocidade, o Antero que nessa altura estava ausente em Paris, na sua dolorosa experiência de proletariado: "E tu sabes - continua Eça a Carlos Mayer - qual era o grande espírito, hoje longe de nós, que explicava Proudhon com a serena familiaridade dos sábios..." (Ibidem). Geração, porém, que personificou uma crise de desdeificação progressiva, que leu Renan com fascínio, que acreditou na Ciência e no Positivismo... "Nós, meu amigo, somos uma geração desiludida por três revoluções, amolecida por uma invenção horrível - a música, tomada da dúvida religiosa, geração que vê esvaecer-se Cristo, quem tanto tempo amou, e não vê chegar a liberdade, por quem há bastante tempo espera". Assim - acrescenta - "Quaes podem ser as obras desta geração? Criações febris, convulsões cerebrais idealistas e doentias, todo um pesadelo moral". (Ibidem)

Quando Antero colabora com poemas "fradiquianos" na Revolução de Setembro (em 1869), é ainda um "romantismo essencial" que pulsa nos seus versos, onde surgem símbolos religiosos, aparições nocturnas, um fundo originalmente sentimental e romântico (como, de resto, se explica na apresentação dos primeiros versos de Fradique na Revolução de Setembro, Lisboa, 29 de Agosto de 1869). Romântico - na ingénua imitação satânica baudelaireana...: "Esta tendência profundamente pessoal e originalmente romântica (...) que chamam poesia satânica, quase não tem tido em Portugal representantes (...)" - e que por isso agora a Revolução de Setembro, em 1869, nos tempos do Cenáculo, apresenta sob as roupagens do Fradique, heterónimo de Antero.

O Romantismo acentuara, contra a Razão iluminista, o novo império do coração, da loucura e do génio: "La Raison me tue; je voudrais être fou être sain" (Rousseau, Correspondance). O coração não só "inspira" como também fornece conhecimentos. O Sturm and Drang proclamara o domínio do génio, "a espontânea, a poderosa força", de que fala o Fausto de Goethe. Mas essa força não bastava agora, se não fosse também cerebralizada, posta ao serviçoda Revolução, "poesia, voz da Revolução", nos novos Cânticos, nas Odes dos tempos modernos de Antero ou na Alma Nova do seu contemporâneo Guilherme de Azevedo. Mais ideias que sentimentos, menos poesia do que a queria Antero, abafada num proselitismo filosófico e torrencial que lhe 
nãodeixa de ser criticadoa propósito da romântica "QuestãoCoimbrã"...

"(...) Desde a lepra dos corpos e os abrolhos

Dos montes arrancados... desde as flamas

Tiradas ao trovão... até às escamas

Arrancadas aos cegos de seus olhos".

"A Física - comenta ironicamente Ramalho (na "Literatura de Hoje", 1866) - ficou sabendo que o trovão é composto de flamas e a Anatomia aprendeu que o olho era feito de escamas..."

Curioso notar como o próprio Antero considerava as Odes Modernas um mau livro, excessivo e romântico, ainda que portador de uma grande e generosa ideia:

"Como arte é um mau livro: excessivo, sem proporção, romântico e algo extravagante. Como poesia é uma nobre poesia aquela, uma nobre loucura como eu não torno a ter outra porque o meu coração endurece à maneira que se incrusta de juízo. (...) Como livro romântico que é, tem o bom e o mau da escola, isto é: os defeitos e os vícios das suas virtudes e belezas" $\left({ }^{3}\right)$.

Assim, o Romantismo em Portugal não deve ser limitado às duas gerações $-1^{\text {a }}$ geração, de Garrett e de Herculano, $2^{\mathbf{a}}$ geração, de Camilo ou de meados do século e dos ultra-românticos - mas, como tem sido já salientado, alargado a uma $3^{a}$ geração romântica, istoé, os românticos que também e ainda foram muitos dos homens da geração de 70. Nesse sentido, pode ler-se no trabalho de tese de Álvaro Manuel Machado sobre os romantismos em Portugal $\left({ }^{4}\right)$ que é preciso aceitar "en principe le pluriel romantismes comme étant une terminologie plus adéquate à cet emiettement des sources romantiques étrangéres au Portugal au long de plus d'un siécle et demi".

Ainda, pois, que romanticamente anti-românticos, os homens de 70 foram marcados pela sensibilidade romântica como atitude perante a vida. Antero, pelos seus confessados fogachos de um temperamento meridional, assumiu, até mais do que outros, do que o mais cerebral

(3) Carta a José da Cunha Sampaio, (Coimbra, 6 de Setembro de 1869) apud, A. de Quental, Cartas I, Universidade dos Açores/Editorial Comunicação, 1989, p. 49) (cartas coligidas, introduzidas e anotadas por Ana Maria de Almeida Martins).

(4) Les Romantismes au Portugal, Modèles Étrangers et orientations nationales, Paris, Gulbenkian, 1986. 
Eça de Queirós, esses arrebatamentos "revolucionários" ou essa estética de raiz bocageana que está visível nos sonetos, cujo intimismo, culto da Noite, pessimismo são de acento romântico.

É ainda romantico, quando, no Casino, fazendo-se eco da historiologia de Herculano a propósito da enfiteuse e da não existência de Feudalismo na Península, condena o "espectro torvo do castelo feudal que não ensombra os nossos vales", ou condena ainda, com ardor romântico e carga metafórica, o Convento de Mafra, essa "magnífica ninharia" que era preciso atulhar de frades, cónegos e capelães...

É também romântico quando romanticamente conjura com os emissários da Internacional Socialista, em 1871, num barquinho a remos, ao luar, no Tejo... Era a sua paixão de reformar o Mundo.

Este episódio do ano de 1871, antecedendo pouco as conferências do Casino, merece uma referência mais desenvolvida. A ele se referem Jaime Batalha Reis, no artigo "Anos de Lisboa", no In Memorian de Antero(1896), Alberto Machado da Rosa, em "Um episódio romântico: a fundação da Internacional em Lisboa (1871)", em Estética do Romântismo em Portugal (Lisboa, Grémio Literário, 1974) e principalmente Anselmo Lorenzo, célebre internacionalista espanhol, em $E l$ Proletariado Militante (Memorias de um Internacional $\left(1^{2}\right.$ ed., Barcelona, 1901; $3^{a}$ ed. Toulouse, 1946, 1947)), que citamos de acordo com o anteriormente referido artigo de Machado da Rosa.

Na primavera de 71, três internacionalistas, Mora, Morago e o citado Lorenzo, haviam chegado a Lisboa e contactado com Antero e Batalha Reis (principalmente por mediação de José Fontana). O quarto de Batalha Reis fora algum tempo a secreta "fornalha" revolucionária. Mas o que Machado da Rosa chama o "episódio romântico" é o encontro no Tejo, num bote alugado, durante horas, enquanto o próprio Batalha Reis remava e "Antero discutia com os emissários socialistas a revolução operária que já lavrava na Europa..." - conta o próprio Batalha Reis no artigo citado.

Quanto às memórias de Lorenzo, referem o empenhamento desse encontro no Tejo, acabando alta madrugada em "formosas melodias" que reflectiam o amor à liberdade e à fraternidade entre os homens. $O$ pior fora que, por causa desse entusiasmo, os jovens haviam quase incorrido nos riscos de serem detidos por uma sentinela do arsenal, que lhes chegara a gritar "quem vem lá...". Dessa "romântica" noite pode dizer Machado da Rosa, também com algum entusiasmo, que "talvez 


\section{Antero romântico}

o maior valor dessas páginas (de Lorenzo) não se reporta a factos, mas a inovações e sentimentos". Ou ainda com igual entusiasmo sublinha "aquela inefável vivência que se radica na mais profunda dimensão do homem: o instinto da liberdade, o sentido da fraternidade universal, e a consciência de que nós podemos moldar o mundo à imagem dos nossos sonhos.

E tudo isto é romântico radicalmente" $\left({ }^{5}\right)$.

Não menos "romântica" se nos afiguram as vivências de Antero na "Sociedade do Raio", fundada em Coimbra naqueles já longínquos anos da contestação ao Reitor Basílio Pinto (nos primeiros anos académicos de Antero). O papel preponderante do "Príncipe da Mocidade", a raiz carismática e ritual da Sociedade do Raio envolvendo juramento e compromissos peculiares às sociedades secretas, levam-nos a afirmar que estes românticos dos anos 60 teriam herdado da $1^{\text {a }}$ geração romântica o entusiasmo revolucionário do vintismo e a paixão pelas sociedades secretas, tão comum nesse período das "lojas" maçónicas que proliferaram em Portugal na $2^{\mathbf{a}}$ década do oitocentismo. Era, de resto, a grande primeira fase combatível do Antero de Coimbra, a que se iriam sucessivamente suceder outras formas de combatividade e angústia, que caracterizaram a sua vida como poeta e como apóstolo da justiça social.

Românticos são os indíviduos que se regulam pelo sentimento e não pela razão. Românticos - e falhados porque românticos - se consideraram Carlos e Ega no fim d' Os Maias. Mas o romantismo de Antero não é o impulso meramente sentimental, o sentimento $v s$ razão que se sistematiza na teoria do Romantismo; é antes e para além disso a profunda pulsão que o leva à ideal procura da identidade global com o Universo, ao "sentimento pensado e ao pensamento sentido", à fusão última do saber com o cosmos.

Nele, tantas vezes confessadamente abúlico e depressivo, como ainda melhor se vê no conjunto das Cartas agora seriadas cronologicamente e publicadas por Ana Maria Almeida Martins (Obras Completas de Antero, Universidade dos Açores/Editorial Comunicação), a morte pensada, o suicídio apenas precipitado pelas crises familiares naquele Setembro de 1891 em S. Miguel, não são mais do que uma

(5) Machado da Rosa, "art. cit.", ob. cit., pp. 62-63. 
outra forma de afirmação da sua busca angustiada. Em certos caracteres, o suicídio, ou a morte, não são mais do que a outra forma de afirmação perante a vida, pela negativa. Quem não consegue afirmar-se pela positiva, afirma-se pela negativa, como se a vontade de não ser fosse tão grande em sua potência como a sua própria vontade de ser. "Hay otra manera de satisfacer ese necessidad de transcendencia: si no puedo crear vida, puedo destruir-la. Destruir la vida tambien es transcender-la", escreve Erich Fromm ( $\left.{ }^{6}\right)$. É precisamente esta "destrutividade", alternativa da "criatividade", que é também consequência da vida não vivida e transcendida pela Morte, porta estreita para "o outro lado" da Vida. Romântico, portanto, não simplesmente porque suicida, porque nem todo o suicida é romântico, um homem do "sentimento imediato", do coração vs razão ou cérebro. A morte como saída/entrada não fora, aliás, procurada pela primeira vez em 91, como se sabe. Esta vingança calma contra a vida vem como uma lenta elaboração, o resultado do lento percurso de um corpo atormentado e de um espírito angustiado, que desembocam nessa negativa afinal, que contudo é afirmação, ainda que a última consciente, em busca do descanso "na mão de Deus eternamente" - ou da Liberdade, "Mors Liberatrix",

Cavaleiro vestido de armas pretas,
E.
E, sendo a Morte, sou a Liberdade.

A Morte é, com efeito, ideia e ocorrência insistentes na poesia anteriana. Seja o Cavaleiro, seja a "funérea Beatriz da mão gelada", seja a própria ideia esparsa e negativista do desespero, da dúvida, da angústia metafísica, em Antero a ideia de negação, de "percurso por nada e para o nada" torna-se quase obsessiva.

Para além do Universo luminoso,

$\cdots$

Abre-se como um vácuo tenebroso.

(6) Psicoanalisis de la Sociedad Contemporanea, 3." edição, México-Buenos Aires, Fondo de Cultura Economica, 1960, cap. III, p. 40. 
A onda desse mar tumultuoso

Vem ali expirar, esmaecida...

...

Termina ali o ser...

E quando o pensamento, assim absorto, Emerge a custo desse mundo morto

E torna a olhar as coisas naturais,

À bela luz da vida, ampla, infinita,

Só vê com tédio, em tudo quanto fita,

A ilusão e o vazio universais.

Veja-se como há uma ideia de movimento neste soneto ("Nirvana", a Guerra Junqueiro), movimento, porém, que se destina, como no caso do Cavaleiro Andante (que vem encontrar apenas escuridão e nada mais...) a desembocar na ilusão e no vazio universais... Repare-se como o movimento é sugerido por "para além", "a onda desse mar tumultuoso", "vem", "emerge"; note-se ainda o contraste entre "a bela luz da vida" e "a ilusão e o vazio", contraste acentuado pelo "só vê". Estes processos de construção "clássica" do soneto, em cujo verso final se contém a verdade essencial e inculcar, estão aqui a servir uma ideia de profundo pessimismo cósmico, a partir de elementos aparentemente "reais", concretos, naturais - a onda, a luz, as coisas naturais - mas transfiguradas prontamente em símbolos de uma linguagem de alcance filosófico e metafísico. Nada tem de romantismo "alma" ou estado de alma/ natureza. Os elementos do real - aliás pouco numerosos em todo o conjunto dos sonetos de Antero, são apenas figurações ou pretextos para uma poesia de tortura metafísica.

A poesia de Antero é, como se sabe e já o dissera Oliveira Martins no Prefácio dos Sonetos, uma poesia hierática, subjectiva, "psicológica e dantesca", que não pinta ou descreve. Prova disso são os cavaleiros, os palácios encantados, as ilhas fantásticas, as visões transcendentais, as formas de "corporizar" angústias e vivências de procura ou intuição do transcendente. Não é no mundo real que se baseia a poesia anteriana, mas no mundo ideal em que se movem as suas abstracções e as suas especulações metafísicas. Há no entanto, uma força íntima, um "excesso", uma violência e um certo retoricismo que lembram de facto os 
processos românticos. Se estamos perante a poesia "de ideias" ou de combate das Odes, por exemplo, o seu "romantismo" é o seu excesso, a sua amplificação retórica, que volta a estar presente mesmo na prosa do Casino como já se referiu. Que é o "espectro torvo do castelo feudal", não "assombrando os nossos vales", senão uma imagem simbólica e romântica com que quer dizer que não houve a tirania do feudalismo na Península?! Como interpretar o quiasmo final da conferência sobre a Decadência dos Povos Peninsulares senão como um processo retorico-romântico com que se apela para o ouvinte e se lhe fala da Revolução como o Cristianismo do mundo moderno?! Isto é, afinal, uma interpretação religiosa da História... E o elemento fundamental aí não é a Razão, mas sim o sentimento...

$\mathrm{O}$ mundo dos sonetos anterianos lembra por vezes o do grande sonetista seu antecessor, Bocage. Como em Bocage, também em Antero há a presença da Dor, da Noite, do vocabulário que transmite uma conotação do "excessivo", do doloroso, do expectante. Mas a "linguagem do coração" bocageana, frequentemente do Amor, do Ciúme, da Ausência ou da traição da mulher amada, em Antero volve-se mera abstração, transposta para o domínio das ideias. A Dôr é a dor da dúvida, o desespero é o do homem perante a (in)existência de Deus, é o percurso da alma que, como o cavaleiro, cai exausta, desiludida, encontrando apenas o vazio a escuridão. Profundamente marcado por vivências religiosas, Antero até nos anos de luta, na própria polémica conferência do Casino sobre a decadência dos povos peninsulares, usa uma linguagem religiosa, ao falar, logo no início, em arrependimento, em contrição, "o acto de contrição pelos nossos pecados históricos", ao lembrar que o pecador se humilha perante o seu Deus, procurando emendar-se, e ao apelar para a regeneração da sociedade $\left({ }^{7}\right)$. E, como se viu, ao terminar a célebre conferência, é ainda à religião cristã que vai buscar a comparação Cristianismo/Revolução na dinâmica da "regeneração" das respectivas sociedades. Por outro lado, é ainda numa linha culta - ou seja a linha do próprio culto mariânico - que

(7) Já na 1." Conferência Antero falara na "questão de saber como deve regenerar-se a organização social" (sublinhado nosso). Independentemente do movimento propriamente chamado a Regeneração (1851), a ideia de regeneração é importante em todoo séc. XIX em Portugal. Veja-se o recente livro de Joel Serrão, Da "Regeneração" à República, Lisboa, Livros Horizonte, 1990. 
vemos subjacente ao célebre soneto "A Virgem Santíssima", onde, mais uma vez, o poeta não descreve nem pinta, mas exprime uma exaltação estético-mística.

Alguém disse que a Vida, para os que pensam, é uma comédia, para os que sentem, é uma tragédia. Antero, porém, é um caso do pensamento e do sentimento em dramático conflito. Ele próprio disso teve consciência desde cedo.

A sua "tragédia" é a dos que sentem o que pensam e pensam o que sentem. Enquanto filosofo, vem-lhe à ideia o sentimento que o atormenta: mas é o poeta que lhe "dilui" o pensamento, que lhe dá, como Eça explicou no seu "Um Génio que era um Santo" (1896), o carácter de caso de "tradução lírica de uma angústia metafísica". Ou, como diria romanticamente Goethe, "se a tua dor te aflige, faz dela um poema". 